\title{
Accurate aging of juvenile salmonids using fork lengths
}

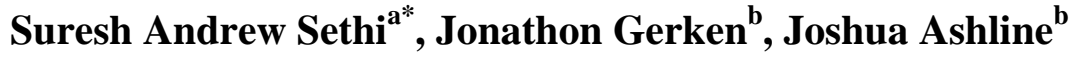 \\ ${ }^{a}$ US Geological Survey, New York Cooperative Fish and Wildlife Research Unit, 211 Fernow Hall, Cornell \\ University, Ithaca NY 14853, USA \\ ${ }^{\mathrm{b}}$ US Fish and Wildlife Service, Anchorage Field Office, 4700 BLM Road, Anchorage, AK 99507, USA
}

\begin{abstract}
Juvenile salmon life history strategies, survival, and habitat interactions may vary by age cohort. However, aging individual juvenile fish using scale reading is time consuming and can be error prone. Fork length data are routinely measured while sampling juvenile salmonids. We explore the performance of aging juvenile fish based solely on fork length data, using finite Gaussian mixture models to describe multimodal size distributions and estimate optimal agediscriminating length thresholds. Fork length-based ages are compared against a validation set of juvenile coho salmon, Oncorynchus kisutch, aged by scales. Results for juvenile coho salmon indicate greater than 95\% accuracy can be achieved by aging fish using length thresholds estimated from mixture models. Highest accuracy is achieved when aged fish are compared to length thresholds generated from samples from the same drainage, time of year, and habitat type (lentic versus lotic), although relatively high aging accuracy can still be achieved when thresholds are extrapolated to fish from populations in different years or drainages. Fork lengthbased aging thresholds are applicable for taxa for which multiple age cohorts coexist sympatrically. Where applicable, the method of aging individual fish is relatively quick to implement and can avoid ager interpretation bias common in scale-based aging.
\end{abstract}

\section{Keywords}

aging, juvenile fish, length frequency, mixture models, Pacific salmon,

*Corresponding author. Tel.: +1 607255 7273; fax: +1 6072551895 .

Email addresses: suresh.sethi@cornell.edu, sasethi@gmail.com (S.A. Sethi) 


\section{Introduction}

Several Pacific salmon species (Oncorynchus spp.) exhibit diversity in pre-smolt freshwater rearing residency times, leading to overlap of young of year and older juvenile cohorts within freshwater habitats. Juvenile salmon life history strategies, survival, and habitat interactions may vary by age cohort (e.g. Bisson et al., 1988; Dolloff and Reeves, 1990; Keith et al., 1998; Myrvold and Kennedy, 2015), such that age-specific studies may provide more detailed insight into juvenile salmon ecology than generic stage-specific studies on mixed age cohorts. One obvious complication in such efforts is a need to age individual juvenile salmon captured as part of field studies into annual cohorts. For example, age-specific survival modeling based upon capture histories from tagged fish (Carlson et al., 2008), age-specific habitat use studies (Bradley et al., In press.), and ontogenic diet studies (Richardson et al., 2016) require ages for individual fish.

Aging of juvenile salmon to an annual cohort is possible using scale reading analysis (e.g., Gilbert, 1912; Quist et al., 2012). However, the process of reading scales can be error prone and time consuming (e.g., Campana, 2001). Furthermore, scale collection may negatively impact handled fish by increasing handling stress responses and interfering with slime and scale protection against disease (e.g., Gadomski et al., 1994), potentially influencing outcomes from studies that require repeated observations on individuals (e.g., age-specific survival estimation via mark recapture analysis). In contrast, collection of fork length measurements may be less invasive. Owing to the discrete timing of salmon spawning events, young of year and older age cohorts of juvenile salmon typically exhibit a strong size differential. An alternative method of determining ages can be implemented by characterizing the size frequency of a population of juvenile salmon of interest and then separating out age cohorts by size thresholds.

Aging by size has been implemented in a number of juvenile salmonid ecology studies. However, determination of ages is often conducted by subjective classification of animals into cohorts after visually inspecting a size frequency histogram (e.g., Keith et al., 1998; Myrvold and Kennedy, 2015). For cases with clearly separated size distributions between age cohorts, visual assessment of age-separating length thresholds can be straightforward (e.g., Fig. 1a). However, in many cases, sparse data or overlapping size distributions among age cohorts can make such visual assessments difficult (Fig. 1b; Crone and Bond, 1974). An alternative, objective approach, to aging fish based upon fork length measurements is to use Gaussian $K$-component finite mixture models (McLachlan and Peel, 2000) to describe the size distribution of mixed-age samples and subsequently determine an optimal age-separating size threshold based upon a misclassification error minimization criteria.

Application of finite mixture models - which describe a multimodal distribution shape as a weighted combination of component distributions-have been applied to size frequency distributions of fish species, with most applications focused on assessing the growth of marine species by tracking size modes across age cohorts, and over time if repeated samples are available (e.g., Fournier et al., 1990; Leigh and Hearn, 2000; Laslett et al., 2004; Macdonald and Pitcher, 1979; Van Beveren et al., 2014). In these applications, termed "modal analysis," finite mixture distributions are first fitted to length frequency data. Subsequently, mixture model output on mean size at age, i.e., the means of the underlying component distributions making up the mixture distribution, are then fit to a growth equation. In addition to information on growth, finite mixture models have also been used to estimate the proportions of different age cohorts in a sample of fish (e.g., Zhu et al., 2013), whereby age proportions are parameters directly 
estimated during finite mixture model fitting (i.e., underlying component distribution weights, or $\boldsymbol{\tau}$ parameters from Eqn 1 below).

Here, we implement finite mixture models on length frequency information to address a separate, but related, problem, namely of aging individual juvenile fish based solely on their lengths. While finite mixture models can predict membership in a specific underlying component distribution-i.e. age cohort - for data in the sample used to fit a model, we develop a bootstrapping routine to utilize fitted mixture models to estimate optimal age-separating fork length thresholds for application to out-of-sample data. Once estimated, age-discriminating length thresholds provide a rapid means of objectively aging fish based upon length measurements for populations exhibiting sizes from two or more age cohorts. We assess the accuracy of aging based upon fork length distributions against traditional scale-based aging using data on juvenile coho salmon, $O$. kisutch, from the Big Lake watershed in southcentral, Alaska. In addition we examine whether age-separating thresholds are useful when applied across populations, and examine whether age-separating length thresholds remain accurate when applied to fish sampled in different years or times of year. Results indicate that for juvenile fish taxa exhibiting length structure across multiple sympatric cohorts such as coho salmon, aging based upon fork length data can be achieved with small to moderate sized samples of fork lengths on the order of 100 fish or greater, achieving aging accuracies of $95 \%$ or better as compared to validation samples assessed by multiple scale readers.

\section{Methods}

\subsection{Age-discriminating fork length threshold estimation with mixture models}

Fork length data samples were separated into component age cohorts using univariate $K$ component Gaussian finite mixture modeling implemented using the mclust package in the $\mathrm{R}$ statistical programming environment (Fraley and Raftery, 2006; R CoreTeam, 2015). Kcomponent Gaussian finite mixture models represent multimodal distributions with an additive mixture of Normal component distributions. In the context of juvenile fish aging, this amounts to separating out different component length distributions specific to age cohorts from samples on a population made up of mixed ages (e.g., Fig. 1). mclust implements maximum likelihood methods to fit mixture models using the Expectation Maximization algorithm (McLachlan and Peel, 2000), where the likelihood is expressed as:

$$
L(\boldsymbol{\tau}, \boldsymbol{\mu}, \boldsymbol{\sigma} \mid \boldsymbol{y})=\prod_{i=1}^{n} \sum_{k=1}^{K} \tau_{k} f\left(y_{i} \mid \mu_{k}, \sigma_{k}\right)
$$

where $\boldsymbol{y}=y_{1}, \ldots, y_{n}$ is a vector of fork lengths, $\boldsymbol{\tau}=\tau_{1}, \ldots, \tau_{k}$ represents the probabilities that a randomly drawn data point comes from a particular component distribution with the constraints that $\tau_{k} \in[0,1]$ and $\sum_{k=1}^{K} \tau_{k}=1$ for $k=1, \ldots, K$, and $f\left(y_{i} \mid \mu_{k}, \sigma_{k}\right)$ represents the probability of the observed data given the parameters specifying a Normal distribution for the $k$ th component:

$$
f\left(y_{i} \mid \mu_{k}, \sigma_{k}\right)=\frac{1}{\sqrt{2 \pi \sigma_{k}^{2}}} \exp \left(-\frac{\left(y_{i}-\mu_{k}\right)^{2}}{2 \sigma_{k}^{2}}\right)
$$

The $\tau$ parameters are interpreted as the proportion with which the $k$ th component is present in the population (e.g., the proportion of young of year fish in the sampled population). The likelihood in Eqn 1 is maximized in choice of the proportions with which the underlying component distributions are present in the population, and their means and variances, given $K$, the total number of component distributions present, and given a specification for the covariance structure across the component distributions. With univariate data, the latter problem simplifies: 
either component variances are equal or they vary across components. The number of underlying component distributions and the covariance structure across component distributions are specified in advance and are not directly estimated in the model. Coho salmon typically spend one to two years in freshwater after emergence from eggs, with a smaller proportion of individuals remaining for additional years in freshwater (Groot and Margolis, 1991). Henceforth, we refer to salmon ages following the "European" system, whereby ages of juvenile salmon correspond to winters after emergence spent in freshwater (Jearld, 1983; Mosher, 1968). For example, a two-year-old juvenile coho salmon has spent two winters in freshwater after emergence from egg in the springtime of a given year. In the Big Lake watershed, the majority of juvenile coho salmon spend one winter in freshwater before smolting and thus a priori we specified two-component finite mixture models with a goal of separating out young of year versus age 1+ fish when examining fork length samples from the openwater summer and Fall field season (see case study data below). Information theoretic model selection could also be used to make inference as to what is the appropriate number of component mixtures, i.e. age cohorts, to describe a sample population; however, in this present example, prior life history information indicated a need for a two-component model (cf., Hunt and Jorgensen, 1999; Laslett et al., 2004). In contrast, prior information was unavailable to indicate whether component distributions representing age cohorts would have equivalent or different variances and thus we used Bayesian Information Criterion scores output by mclust to select the appropriate mixture distribution variance structure.

We estimated an optimal age-discriminating fork length threshold by simulating fork length data with known component distribution membership, i.e. known "age", from a fitted mixture distribution using the sim\{mclust\} function. Subsequently, a grid search over a vector of candidate length thresholds (rounded to $1.0 \mathrm{~mm}$ ) was used to find the optimal age-discriminating length threshold, $d^{*}$, which minimized a classification error problem:

$$
\min _{d} \sum_{m=1}^{M} \operatorname{abs}\left(C\left(l_{m} \mid d\right)-A\left(l_{m}\right)\right)
$$

where $d$ is the a candidate age-discriminating fork length threshold, $l_{m}$ is a fork length randomly drawn from the fitted mixture distribution for $m=1, \ldots, M$ draws, $C\left(l_{m} \mid d\right)$ is the age class assigned to the fork length datum given a candidate length threshold, and $A\left(l_{m}\right)$ is the true membership of the random fork length draw, which is known because data are simulated from the fitted mixture distribution. We simulated a large number of fork lengths from a fitted distribution in estimating of $d^{*}$, setting $M=100,000$ to stabilize age-discriminating length threshold estimates. Conditional upon the finite mixture distribution being an adequate representation of the mixed-age fork length distribution, the misclassification rate based upon the $M$ simulated fork lengths for a given $d^{*}$ provides a performance metric assessing the overall aging accuracy of the mixture model-based aging estimator across all fish sizes, i.e. so called aging "process error" following Campana (2001; henceforth referred to as the "model-based misclassification rate"). Similarly, one minus the model-based misclassification rate is an assessment of predicted overall aging accuracy.

Finally, we implemented a parametric bootstrap routine to estimate uncertainty associated with estimates of $d^{*}$. We generated 500 bootstrap datasets by resampling with replacement from a given fork length sample. For each bootstrap dataset, a two-component mixture model was fitted with the same variance structure as with the model fitted to observed data, the bootstrap fitted model was used to simulate known membership fork length data and generate an estimate 
of $d^{*}$ by minimizing the classification error problem in Eqn 3, and finally $2.5 \%$ and $97.5 \%$ quantiles were calculated to generate a $95 \%$ confidence interval for $d^{*}$. Example R code to fit a mixture distribution, estimate $d^{*}$, and conduct the boostrap routine is provided in Supplemental Text S1.

\subsection{Validation trials}

We tested the performance of the mixture model fork length-based aging approach against a sample of juvenile coho salmon aged by five scale readers. Two separate datasets were utilized for this analysis. First, a large multiyear collection of juvenile coho salmon fork lengths were collected throughout Meadow Creek and Fish Creek drainages within the Big Lake watershed in south central Alaska, U.S.A., as part of a larger portfolio of salmon ecology projects (samples from 2011-2015, June to October; Fig. 2). The Big Lake watershed drains $230 \mathrm{~km}^{2}$ of area and waters terminate at saltwater in Upper Cook Inlet. Streams in the Big Lake watershed are largely groundwater driven (Hogan, 1995). Sampled lotic environments were predominately low gradient first through third order streams; lentic environments varied from eutrophic to oligotrophic depending upon lake depth and position within watershed. Fish in lotic environments were collected with $6 \mathrm{~mm}$ wire mesh minnow traps baited with sodium sulfite-free cured salmon roe (Clements et al., 2011), and fish in lentic environments were collected using a combination of minnow traps and small fyke nets $(0.75 \mathrm{~m}$ by $1.25 \mathrm{~m}$ fyke net, $5 \mathrm{~m}$ lead). Fyke nets were assumed not to have size selectivity. Minnow traps may have been selective against very large juveniles (e.g. lower efficiency at catching fish $>150 \mathrm{~mm}$ ), however, large juvenile fish were believed to be rare in the system and assumed not to affect aging results (see below). These fork length data were used to estimate age-discriminating length thresholds, stratified by year, drainage, time, and habitat type (lentic versus lotic).

Second, in 2015, a subset of fish collected during minnow trap and fyke net sampling were selected for aging by scale reading. Approximately 5-10 scales were collected from each fish and examined under 10-50 magnification with a stereomicroscope. Five readers estimated the age of juvenile coho salmon without access to information on fish size or time of year of collection, to avoid potential interpretation bias; each fish was aged by three or four separate readers. A scale annulus was defined using the criteria of circuli crowding and "cutting over" described by Beamish and McFarlane (1983). Readers aged fish to the year following the "European" aging convention. The occurrence of fish estimated to be greater than 1 year old at the Summer and Fall 2015 sample collection season (i.e. had spent > 1 winter in freshwater) was not common, and discrimination of ages greater than 1 year old was challenging. As such, all ages were subsequently translated to either young of year, or age 1+ fish. Validation data were constructed from fish which generated consensus age 0 or $1+$ ages across all readers, and thus were taken as "true" ages for sample fish. Subsequently, validation fish were aged using a relevant agediscriminating length threshold estimated from the 2011-2015 Big Lake fork length data (validation fish were not included in datasets used to estimate fork length thresholds).

In addition to assessing overall accuracy of the age-discriminating fork length thresholds, we assessed performance of fork length threshold-based aging to a suite of challenge trials designed to assess whether length thresholds could perform across years, times of season, and habitat types (Table 1). Validation samples used to assess accuracy were restricted to those fish with a respective age-discriminating length threshold available in common across all scenarios within a given challenge trial. 


\section{Results}

When all fork length data collected throughout the study $(n=32,584)$ were combined into a single sample and analyzed with mixture models, the young of year versus age 1+ discriminating length threshold was $67.8 \mathrm{~mm}$ (bootstrapped $95 \%$ confidence interval $=(67.8 \mathrm{~mm}, 69.0 \mathrm{~mm})$ ) with an estimated model-based overall misclassification error rate of $11.2 \%$ (Fig. 1b; Table S1). When stratified by drainage (Meadow Creek and Fish Creek), biweekly period within season, and habitat type (lentic versus lotic), the precision of age-discriminating thresholds improved with increasing fork length sample size, although this relationship was weak at small sample sizes and in some cases relatively precise thresholds could be estimated with as few as 25-30 fork length measurements (Fig. 3; Table S1). The model-based overall misclassification rates, i.e. from sampling randomly from a given mixed population of young of year and age 1+ fish consistent with a fitted mixture distribution, ranged from $<0.1 \%$ to $15.5 \%$. The estimated overall misclassification rate was not closely related to sample size, but declined sharply with separation between the mean length of the respective age cohorts (Fig. 4). Under this data stratification, BIC-supported models had equivalent variances for young of year and age 1+ component length distributions in over half of fitted data sets, and in cases where different variances were supported, age 1+ fish always had larger component distribution variance (Table S1).

A total of 627 fish sampled from the Big Lake drainage in 2015 had consensus ages from scale readings (Table S2). When compared against validation samples, the overall aging accuracy from length thresholds estimated from finite mixture distributions was $98.2 \%$ (96.2\% accurate for young of year fish and $99.3 \%$ accurate for age 1+ fish) when fish were aged with thresholds estimated from samples from a respective drainage, biweek period, and habitat type (Table 2 Scenario 1). Aging was still relatively accurate when age-discriminating thresholds were estimated using all fork length samples combined across drainages, years (2011-2015), times within season (June through October), and habitat types, resulting in $94.3 \%$ overall accuracy, although aging accuracy for young of year fish was only $76.2 \%$ in this case (100\% accurate for age 1+ fish; Table 2 Scenario 3). Across all aging trials against validation data, misclassification error rates were highest at intermediate size bins corresponding to lengths at which young of year and age 1+ cohorts overlap (Table 2). For juvenile coho salmon in the Big Lake drainage during the summer and early Fall months, this high error intermediate fork length size bin typically ranged from $65-75 \mathrm{~mm}$. When fork length thresholds were estimated from samples specific to a respective drainage, biweek period, and habitat type, overall aging accuracy in this intermediate $65-75 \mathrm{~mm}$ size bin was $71.4 \%$ as compared to $98.2 \%$ when calculated across all size bins combined (bin-specific error rates are not reported but available from the authors upon request).

Aging accuracy for the validation set of juvenile coho was greater when age-discriminating thresholds were estimated from length samples that matched the biweekly or monthly period from which validation fish were collected. Highest aging accuracy rates were achieved when age-discriminating fork length thresholds were stratified by biweekly period, although monthlyaggregated data produced nearly equivalent aging performance (Table 2, Scenarios 4-5). Aging accuracy showed a decline when fork length samples were aggregated across time within a sampling year (Table 2, Scenario 6). Similarly, aging accuracy was generally better when agediscriminating thresholds were estimated from samples of fork lengths stratified by a respective lentic or lotic habitat type (Table 2, Scenarios 7-10). In this case, the effect was most pronounced when aging young of year fish. 
When examining whether mismatches between fork length collection year versus years in which fish were aged affected accuracy, results were variable across years and age cohorts, although overall accuracy was highest when sampling years matched aging years, for both data stratified by biweekly or monthly periods (Table 2, Scenarios 11-16). Finally, examination of whether age-discriminating fork length thresholds estimated from different (but adjacent) drainages affected aging accuracy was hampered by a lack of Meadow Creek validation fish with an associated age-discriminating fork length threshold estimated from Fish Creek drainage for a given biweek or month $\times$ habitat type combination from 2015. As a result, we compared the 2015 Meadow Creek validation fish against length thresholds estimated from Meadow Creek and Fish Creek from 2012 length samples. In this case, for samples stratified by biweekly or monthly period and habitat type, overall aging accuracy of 2015 Meadow Creek validation fish was relatively stable when assessed with age-discriminating thresholds from lengths from Fish Creek or Meadow Creek in 2012 (Table 2, Scenarios 17-20); accuracy for young of year or age 1+ showed contrasting trends, however, with highest young of year accuracy achieved when length samples and validation fish were taken from the same drainage, but vice versa for age 1+ fish. We caution that these cross-drainage results may be confounded by a year effect in aging 2015 Meadow Creek validation fish with length thresholds from 2012 sampling.

\section{Discussion}

Finite Gaussian mixture models fit to length data provided a straightforward means of aging juvenile fish from populations of mixed aged cohorts. A potential advantage of this aging method, when applicable, is that so called observer 'interpretation error' (Campana 2001) is avoided by taking an objective statistical approach to estimating and applying age-discriminating fork length thresholds. In contrast, traditional scale-based aging of juvenile salmonids can include considerable interpretation error (e.g. Maceina et al., 2007). For example, the juvenile coho salmon scale-aged validation data set utilized here originally included 966 fish. However, approximately a third of these samples included age determination discrepancies across multiple readers.

Validation results for juvenile coho salmon indicated that highest accuracies could be achieved by collecting fork length samples for the purposes of estimating age-discriminating length thresholds from times and habitat types which mirror those for fish to be aged. While not confirmed here, we suspect this result is not specific to coho salmon, and may apply more broadly to other juvenile fish taxa where growth is typically heterogeneous over time and space in freshwater lake and stream systems. In many field scenarios, this sampling situation would fall naturally from fish collection efforts, whereby mixture models could be fit to study site-level data (or some representative subset thereof) to provide age-discriminating length thresholds tailored to a specific collection site and time. Alternatively, validation results from the Big Lake watershed suggested that extrapolation of age-discriminating thresholds beyond areas or times at which fork lengths were collected can still produce good aging accuracy performance. In cases where many fork length data sets are available across habitat types and time, it may be possible to use regression to relate age-discriminating length thresholds to suites of covariates such as environmental information related to growth dynamics to better predict age-discriminating thresholds for previously unsampled populations.

Aging errors were highest in regions where sizes of different age cohorts overlapped. Depending on aging needs, conservatively high accuracy aging could be achieved by restricting length-based aging to fish outside of the transition zone between successive age cohorts. The example R code provided in Text S1 could easily be modified to assess theoretical aging error 
rates over a specified size range, in which case analysts could identify so called "problem" size ranges to avoid in attempting to age fish from estimated age-discriminating fork length thresholds. An implicit assumption in fitting finite mixture models to fork length samples and then subsequently estimating age-separating fork length thresholds is that the growth dynamics from the sample of lengths is representative of a specific statistical population of fish. These growth dynamics, and thus aging error rate estimates, may not necessarily be representative of different sample populations to which age-discriminating length thresholds are applied. In light of this, we caution against extrapolation age-discriminating fork length thresholds too widely across time or systems, and when doing so, to conduct validation efforts by aging a subset of fish using scales to assess accuracy of the extrapolated length threholds.

Utilization of age-discriminating fork length thresholds proved to be an accurate means for aging juvenile coho salmon in southcentral Alaska. We suspect that this aging method may be applicable to other fish taxa and locations in which populations exhibit discrete annual spawning events and thus produce cohorts separated by annual periods of growth. One shortcoming in the application of age-discriminating length thresholds is that sampling need capture sympatric age cohorts such that multimodal size distributions are available for mixture modeling. This precludes some salmonid taxa from aging by length thresholds, such as juvenile chum salmon (O. keta) in freshwater environments which typically migrate to sea during the same year in which they are hatched. In other cases, the length aging threshold could be extended to greater than two component distributions for aging fish beyond two age cohorts. For example, in a related application, Zhu et al. (2013) apply finite mixture modeling methodology to assess age proportions ( $\boldsymbol{\tau}$ from Eqn 1) for samples on American eel populations, Anguilla rostrata, with up to nine age classes. When applicable, aging accuracy from fork length thresholds is likely highest for younger age cohorts as size distributions for older cohorts may overlap due to individual growth heterogeneity and slowing growth as animals reach adult size. Finally, while the analysis here based solely on fork lengths exhibited high aging accuracy for juvenile salmonids, multidimensional mixture models which can include additional individual measurements such as weights, may further improve aging thresholds based upon readily collected data at the time of fish sampling. For example, the mclust package can fit multivariate finite mixture models which could accommodate both length and weight data, in which case age-discriminating thresholds could be based upon combined length and weight cutoffs.

Scale readings continue to provide an important tool for aging juvenile fish. While we anticipate length-based aging as demonstrated here can have advantages over scale-based aging, particularly for individually aging large numbers of juvenile fish, the two methods play a complementary role for producing accurate fish age determination. Specifically, scale-based aging of a subset of a sample of fish can provide information about the number of age cohorts, and thus the choice of number of component mixtures to fit in Gaussian mixture modeling, within a population. Furthermore, scale-based aging can be used to validate estimated agediscriminating length thresholds, particularly in cases when length thresholds are applied across populations. Finally, a combination of length-based aging via mixture models followed by scalebased aging for those fish in the sample in the intermediate size bin near the age-discriminating length threshold could be used to produce accurate ages across all size bins in the sample, while reducing the number of fish needed to be aged by time intensive scale reading.

\section{Acknowledgements}


We thank two anonymous reviwers, A.E. Punt, and other journal editorial staff for comments that improved this article. Funding for this project was provided by the Alaska Sustainable Salmon Fund, the U.S. Fish and Wildlife Service, and the U.S. Geological Survey. We thank the private landowners throughout the Big Lake watershed and the Alaska Department of fish and game for providing access for study sampling. Numerous U.S. Fish and Wildlife Service field technicians are thanked for their sampling efforts. The findings and conclusions in this article are those of the author(s) and do not necessarily represent the views of the U.S. Fish and Wildlife Service. Any use of trade, firm, or product names is for descriptive purposes only and does not imply endorsement by the U.S. Government.

\section{Supplementary Materials}

Text S1. Example R code for mixture model fits and age-discriminating length threshold estimation.

Table S1. Gaussian two-component mixture distribution estimates and 95\% confidence intervals (CI) for age-discriminating length thresholds from juvenile coho salmon fork lengths collected in the Big Lake watershed, Alaska, U.S.A, 2011-2015.

Table S2. Juvenile coho salmon scale age readings validation data, Big Lake watershed Alaska U.S.A., 2015.

\section{References}

Beamish, R.J., McFarlane, G.A., 1983. The forgotten requirement for age validation in fisheries biology. Trans. Am. Fish. Soc. 112, 735-743.

Bisson, P.A., Sullivan, K., Nielsen, J.,1988. Channel hydraulics, habitat use, and body form of juvenile Coho Salmon, Steelhead, and Cutthroat Trout in streams. Trans. Am. Fish. Soc. 117, 262-273.

Bradley, C., Sethi, S.A., Ashline, J., Gerken, J., 2016. Cohort-specific variation in juvenile coho salmon habitat use. Ecol. Freshw. Fish, in press.

Campana, S.E., 2001. Accuracy, precision and quality control in age determination, including a review of the use and abuse of age validation methods. J. Fish. Biol. 59, 197-242.

Carlson, S.M., Olsen, E.M., Vollestad, L.A., 2008. Seasonal mortality and the effect of body size: a review and an empirical test using individual data on brown trout. Funct. Ecol. 22, 663-673.

Clements, S., R. Chitwood, Schreck. C.B., 2011. Effects of commercially available egg cures on the survival of juvenile salmonids. PLoS ONE 6, e21406.

Crone, R.A., Bond, C.E., 1974. Life history of Coho Salmon, Oncorhynchus kisutch, in Sashin Creek, southeastern Alaska. Fish. Bull. 74, 897-923.

Dolloff, C.A., Reeves, G., 1990. Microhabitat partitioning among stream-dwelling juvenile Coho Salmon, Oncorhynchus kisutch, and Dolly Varden, Salvelinus malma. Can. J. Fish. Aquat. Sci. 47, 2297-2306.

Fournier, D. A., Sibert, J. R., Majkowski, J., Hampton, J., 1990. MULTIFAN: a likelihood based method for estimating growth and age composition from multiple length frequency data sets illustrated using data from southern bluefin tuna (Thunnus maccoyii). Can. J. Fish. Aquat. Sci. 47, 301-313.

Fraley, C., Raftery, A.E., 2002 Model-based clustering, discriminant analysis and density estimation J. Am. Stat. Assoc. 97, 611-631. 
Gadomski, D.M., Mesa, M.G., Olson, T.M., 1994. Vulnerability to predation and physiological stress responses of experimentally descaled juvenile chinook salmon, Oncorhynchus tshawytscha. Environ. Biol. Fish. 39, 191-199.

Gilbert, C. H., 1912. Age at maturity of the Pacific Coast salmon of the genus Oncorhynchus. Fish. Bull. 32, 1-22.

Groot, C., Margolis, L., 1991. Pacific Salmon Life Histories, University of British Columbia Press, Vancouver.

Hogan, E.V., 1995. Overview of environmental and hydrogeological conditions near Big Lake, Alaska:U.S. Geological Survey Open-File Report 95-403, Anchorage, Alaska.

Hunt, L., Jorgensen, M., 1999. Mixture model clustering using the MULTIMIX program. Aust. Nz. J. Stat. 41, 153-171.

Jearld, A., 1983. Age determination. Pages 301-324 in Nielsen, L.A., Johnson, D.L. (Eds.), Fisheries Techniques. American Fisheries Society, Bethesda, USA, pp. 301-324.

Keith, R.M., Bjornn, T.C., Meehan, W.R., Hetrick, N.J., Brusven, M.A., 1998. Response of juvenile salmonids to riparian and instream cover modifications in small streams flowing through second-growth forests of southeast Alaska. T. Am. Fish. Soc. 127, 889-907.

Laslett, G.M., Eveson, P.J., Polacheck, T., 2004. Fitting growth models to length-frequency data. ICES J. Mar. Sci. 61, 218-230.

Leigh, G.M., and Hearn, W.S., 2000. Changes in growth of juvenile southern bluefin tuna (Thunnus maccoyii): an analysis of length-frequency data from the Australian fishery. Mar. Freshwater Res., 51, 143-154.

MacDonald, P.D.M., Pitcher, T.J., 1979. Age groups from size-frequency data: a versatile and efficient method for analyzing distribution mixtures. J. Fish. Res. Board Can. 36, 987-1001.

Maceina, M.J., Boxrucker, J., Buckmeier, D.L., Gangl, S., Lucchesi D.O, et al., 2007. Current status and review of freshwater fish aging procedures used by State and Provincial fisheries agencies with recommendations for future directions. Fisheries 32, 329-340.

McLachlan, G., Peel, D., 2000. Finite Mixture Models, Wiley and Sons, New York.

Mosher, K.H., 1968. Photographic atlas of sockeye salmon scales. Fish. Bull. 67, 243-280.

Myrvold, K.M., Kennedy, B.P., 2015. Variation in juvenile Steelhead density in relation to instream habitat and watershed characteristics. Trans. Am. Fish. Soc. 144, 577-590.

Quist, M.C., Pegg, M.A. DeVries, D.R., 2012. Age and growth, in: Zale, A.V., Parrish, D.L., Sutton, T.M. (Eds.), Fisheries Techniques, 3rd edition. American Fisheries Society, Bethesda, Maryland, pp. 677-731.

R Core Team, 2015. R: a language and environment for statistical computing. R Foundation for Statistical Computing, Vienna. https://www.R-project.org/

Richardson, N., Beaudreau, A., Wipfli, M., Finkle, H., 2016. Prey partitioning and use of insects by juvenile sockeye salmon and a potential competitor, threespine stickleback, in Afognak Lake, Alaska. Ecol. Freshw. Fish, in press.

Van Beveren, E., Bonhommeau, S., Fromentin, J.-M., Bigot, J.-L., Bourdeix, J.-H., et al., 2014. Rapid changes in growth, condition, size and age of small pelagic fish in the Mediterranean. Mar. Biol. 161, 1809-1822.

Zhu, X., Zhao, Y., Mathers, A., Corkum, L.D., 2013. Length frequency age estimations of American Eel recruiting to the upper St. Lawrence River and Lake Ontario. T. Am. Fish. Soc. 


\section{Tables}

Table 1. Fork length-based aging challenge trials for juvenile coho salmon data collected from the Big Lake watershed, Alaska, U.S.A. from 2011 to 2015.

Challenge trial

What is the overall aging accuracy of FL thresholds estimated from samples stratified by time, habitat, and drainage, or pooled together?

What is the impact of temporal resolution in estimating FL thresholds on aging accuracy?

Is aging accuracy improved by stratifying FL threshold estimation by habitat type?

Can FL based aging thresholds estimated from one year be used to age fish in different years?

Can FL based aging thresholds estimated from one drainage be used to age fish in different drainages?
Fork
Length,
Fish
Creek,
Meadow
Creek
Acronyms:

Age estimation scenario

Age all 2015 validation fish (MC and FC) with length thresholds estimated from samples stratified by a respective year, drainage, time within season, and habitat; or pool all FL data 2011-2015.

Age MC 2015 validation fish with thresholds from MC 2015 FLs stratified by a respective biweek or month, or pooled across time within season.

Age MC 2015 validation fish with thresholds from MC 2015 FLs stratified by habitat type or pooled across habitat types.

Age MC 2015 validation fish with thresholds from MC 2011 or 2012 FLs.

Age MC 2015 validation fish with thresholds from MC 2012 or from FC 2012 FLs.

Fork


Table 2. Aging accuracy for age-discriminating fork length thresholds.

\begin{tabular}{|c|c|c|c|c|c|c|c|c|c|}
\hline $\begin{array}{l}\text { Scenar } \\
\text { io }\end{array}$ & $\begin{array}{l}\text { Challenge } \\
\text { trial }\end{array}$ & $\begin{array}{l}\text { Validati } \\
\text { on data }\end{array}$ & $\begin{array}{l}\text { Age-discriminating } \\
\text { sampling scenario }\end{array}$ & $\begin{array}{l}n \text { (Age } \\
0)\end{array}$ & $\begin{array}{l}n \quad \text { (Age } \\
1+)\end{array}$ & $\begin{array}{l}\text { Overall } \\
\text { accurac } \\
\text { y rate }\end{array}$ & $\begin{array}{l}\text { Age } 0 \\
\text { accurac } \\
\text { y rate }\end{array}$ & $\begin{array}{l}\text { Age } 1+ \\
\text { accurac } \\
\text { y rate }\end{array}$ & $\begin{array}{l}\text { Highest } \\
\text { aging } \\
\text { error } \\
\text { length } \\
\text { bin (mm) }\end{array}$ \\
\hline 1 & \multirow{3}{*}{$\begin{array}{l}\text { Overall } \\
\text { accuracy }\end{array}$} & $\begin{array}{l}\text { All } \\
2015^{\mathrm{a}}\end{array}$ & $\begin{array}{l}2015 \text { FL } \times \text { drainage }(\mathrm{MC} \text { or FC), biweek, } \\
\text { habitat. }\end{array}$ & 78 & 144 & 0.982 & 0.962 & 0.993 & $66-75$ \\
\hline 2 & & $\begin{array}{l}\text { All } \\
2015^{b}\end{array}$ & 2015 FL $\times$ drainage, month, habitat. & 79 & 164 & 0.955 & 0.949 & 0.957 & $66-75$ \\
\hline 3 & & $\begin{array}{l}\text { All } \\
2015^{c}\end{array}$ & All FL data combined 2011-2015. & 151 & 476 & 0.943 & 0.762 & 1.000 & $66-75$ \\
\hline 4 & \multirow{3}{*}{$\begin{array}{l}\text { Temporal } \\
\text { resolution }\end{array}$} & $\begin{array}{l}\text { MC } \\
2015^{\mathrm{d}}\end{array}$ & MC 2015 FLs $\times$ biweek habitat. & 59 & 71 & 0.969 & 0.949 & 0.986 & $66-75$ \\
\hline 5 & & $\begin{array}{l}M C \\
2015^{\mathrm{d}}\end{array}$ & MC 2015 FLs $\times$ month habitat. & 59 & 71 & 0.962 & 0.932 & 0.986 & $66-75$ \\
\hline 6 & & $\begin{array}{l}\text { MC } \\
2015^{\mathrm{d}}\end{array}$ & $\begin{array}{l}\text { MC } 2015 \text { FLs } \times \text { habitat, pool time within } \\
\text { year. }\end{array}$ & 59 & 71 & 0.923 & 0.831 & 1.000 & $66-75$ \\
\hline 7 & \multirow{4}{*}{$\begin{array}{l}\text { Habitat } \\
\text { stratificati } \\
\text { on }\end{array}$} & $\begin{array}{l}\text { MC } \\
2015^{\mathrm{e}}\end{array}$ & MC 2015 FLs × biweek, habitat. & 45 & 124 & 0.976 & 0.933 & 0.992 & $66-75$ \\
\hline 8 & & $\begin{array}{l}\mathrm{MC} \\
2015^{\mathrm{e}}\end{array}$ & MC 2015 FLs $\times$ biweek, pool habitat. & 45 & 124 & 0.893 & 0.844 & 0.911 & $66-75$ \\
\hline 9 & & $\begin{array}{l}\text { MC } \\
2015^{\mathrm{f}}\end{array}$ & MC 2015 FLs $\times$ month, habitat. & 50 & 152 & 0.965 & 0.980 & 0.961 & $66-75$ \\
\hline 10 & & $\begin{array}{l}\mathrm{MC} \\
2015^{\mathrm{f}}\end{array}$ & MC 2015 FLs $\times$ month, pool habitat. & 50 & 152 & 0.980 & 0.940 & 0.993 & $66-75$ \\
\hline 11 & \multirow{4}{*}{$\begin{array}{l}\text { Collection } \\
\text { versus } \\
\text { aging year } \\
\text { mismatch }\end{array}$} & $\begin{array}{l}\text { MC } \\
2015^{\mathrm{g}}\end{array}$ & MC 2015 FLs $\times$ biweek, habitat. & 34 & 43 & 0.948 & 0.912 & 0.977 & $66-75$ \\
\hline 12 & & $\begin{array}{l}\mathrm{MC} \\
2015^{\mathrm{g}}\end{array}$ & MC 2011 FLs $\times$ biweek, habitat. & 34 & 43 & 0.896 & 1.000 & 0.814 & $76-85$ \\
\hline 13 & & $\begin{array}{l}\text { MC } \\
2015^{\mathrm{g}}\end{array}$ & MC 2012 FLs × biweek, habitat. & 34 & 43 & 0.883 & 0.912 & 0.860 & $66-75$ \\
\hline 14 & & $\mathrm{MC}$ & MC 2015 FLs $\times$ month, habitat. & 59 & 71 & 0.962 & 0.932 & 0.986 & $66-75$ \\
\hline
\end{tabular}




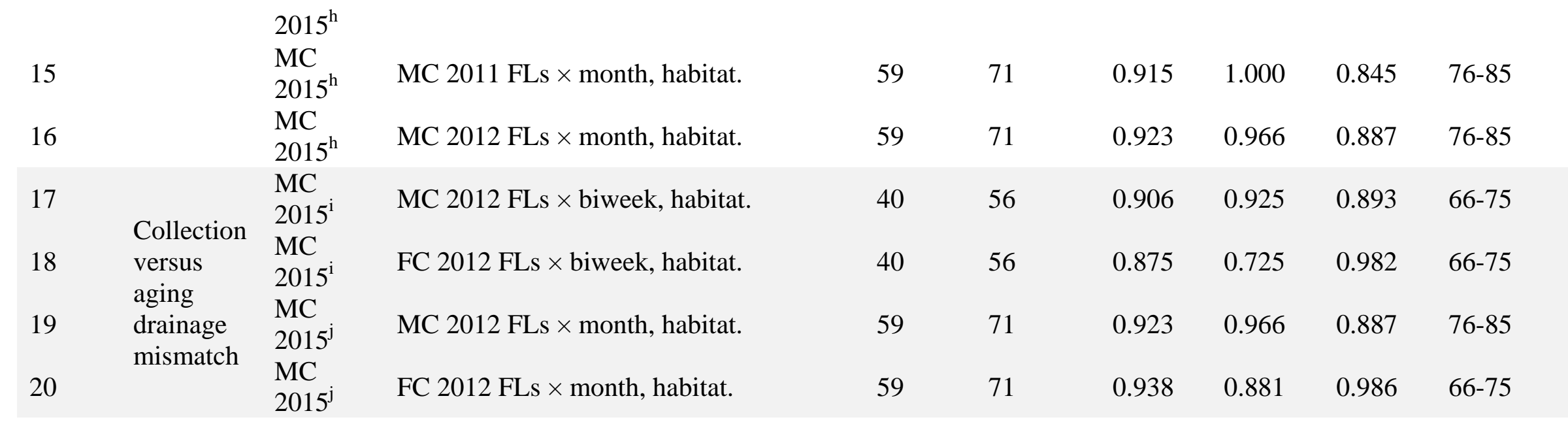

${ }^{\mathrm{a}-\mathrm{j}}$ Superscripts indicate that scenarios within a challenge trials which utilize the same set of validation samples to assess aging accuracy. Aging accuracy = 1 - misclassification rate. Acronyms: Fish Creek, Fork Length, Meadow Creek. 


\section{Figure captions}

Figure 1. Length frequency distributions and fitted two-component Gaussian finite mixture models from samples of juvenile coho salmon (Oncorhynchus kisutch) from the Big Lake watershed, Alaska, 2011-2015. Vertical black dashed line are the optimal ageseparating length threshold based upon fitted mixture distributions and a criteria to minimize classification error with $95 \%$ confidence limits. Panel a: samples from Meadow Creek drainage lotic habitats in 2015 over the biweek period July 1 to July 15 ( $n=523)$. Panel b: all samples combined over 2011-2015 in the Big Lake study region $(n=32,854)$.

Figure 2. Location of the study drainages in the Big Lake region of south central Alaska, U.S.A.

Figure 3. Examination of the relationship between precision of age-discriminating fork length thresholds with sample size (a) and with separation between mean size of component size distributions (b; mean $1=$ smaller sized age cohort, mean $2=$ larger sized age cohort). Data are 95\% confidence interval widths from age-discriminating fork length thresholds estimated from two-component finite mixture models with fork length data on juvenile coho salmon from the Big Lake watershed, Alaska, U.S.A., 2011-2015, stratified by drainage, year, biweek period, and habitat type (lentic versus lotic). Lines represent log normal univariate regression fits and 95\% confidence intervals for fitted lines. Slope estimates with $95 \%$ confidence limits: panel $a=-0.0004(-0.0006,-0.0002)$, panel $b=-$ $0.015(-0.047,0.016)$.

Figure 4. Examination of the relationship between the overall misclassification rate of age-discriminating fork length thresholds with sample size (a) and with separation between mean size of component size distributions ( $b$; mean $1=$ smaller sized age cohort, mean 2 $=$ larger sized age cohort). Data are estimates of the rate at which young of year fish would be misclassified as age 1+ fish based upon fork length information and vice versa across a random sample of lengths throughout the length frequency distribution, from agediscriminating fork length thresholds estimated from two-component finite mixture models with fork length data on juvenile coho salmon from the Big Lake watershed, Alaska, U.S.A., 2011-2015, stratified by drainage, year, biweek period, and habitat type (lentic versus lotic). Lines represent log normal univariate regression fits and $95 \%$ confidence intervals for fitted lines. Slope estimates with 95\% confidence limits: panel $\mathrm{a}=0.0002(<-0.0001,0.0006)$, panel $\mathrm{b}=-0.148(-0.181,-0.115)$. 
a)

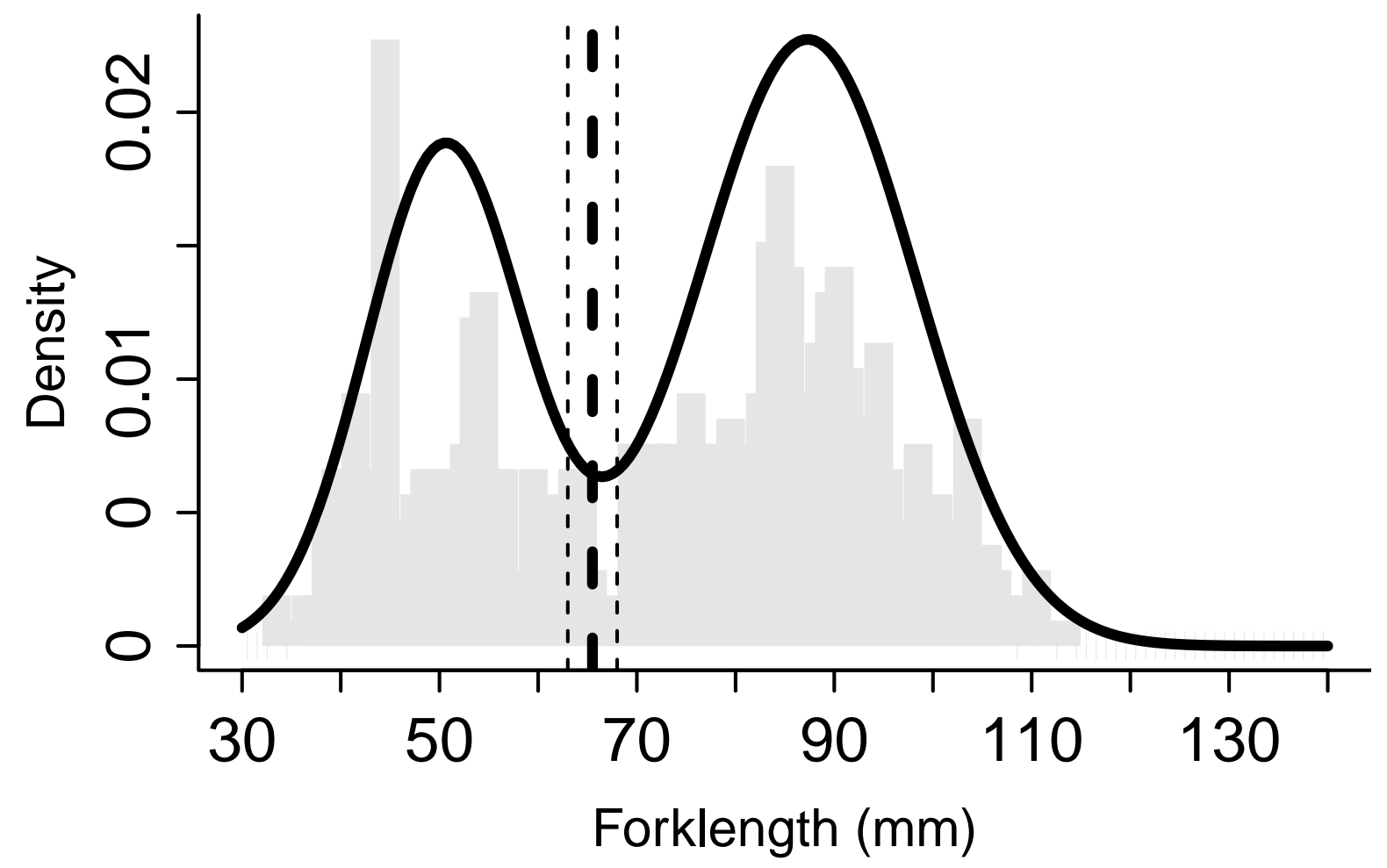

b)

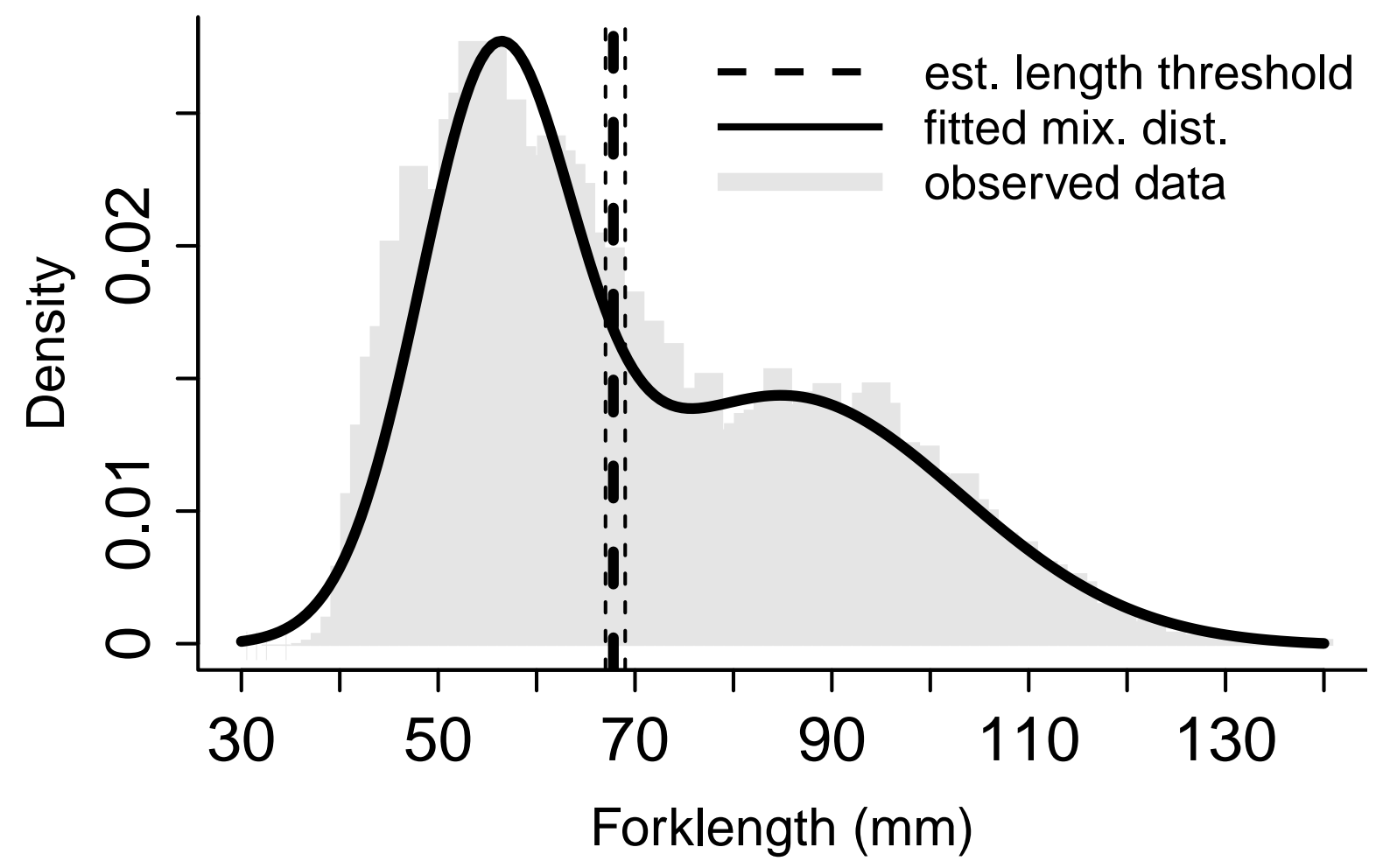


Click here to download high resolution image

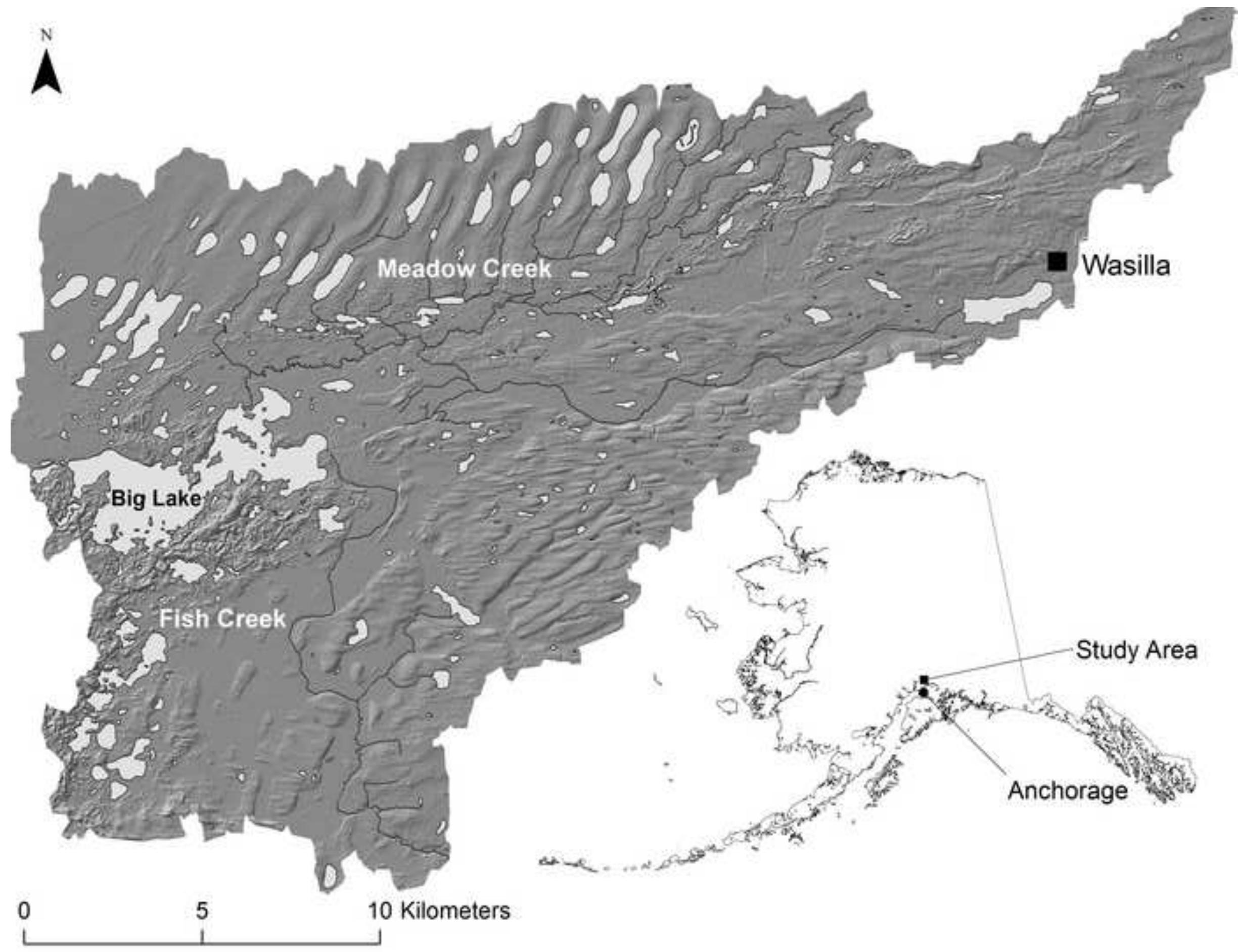


a)

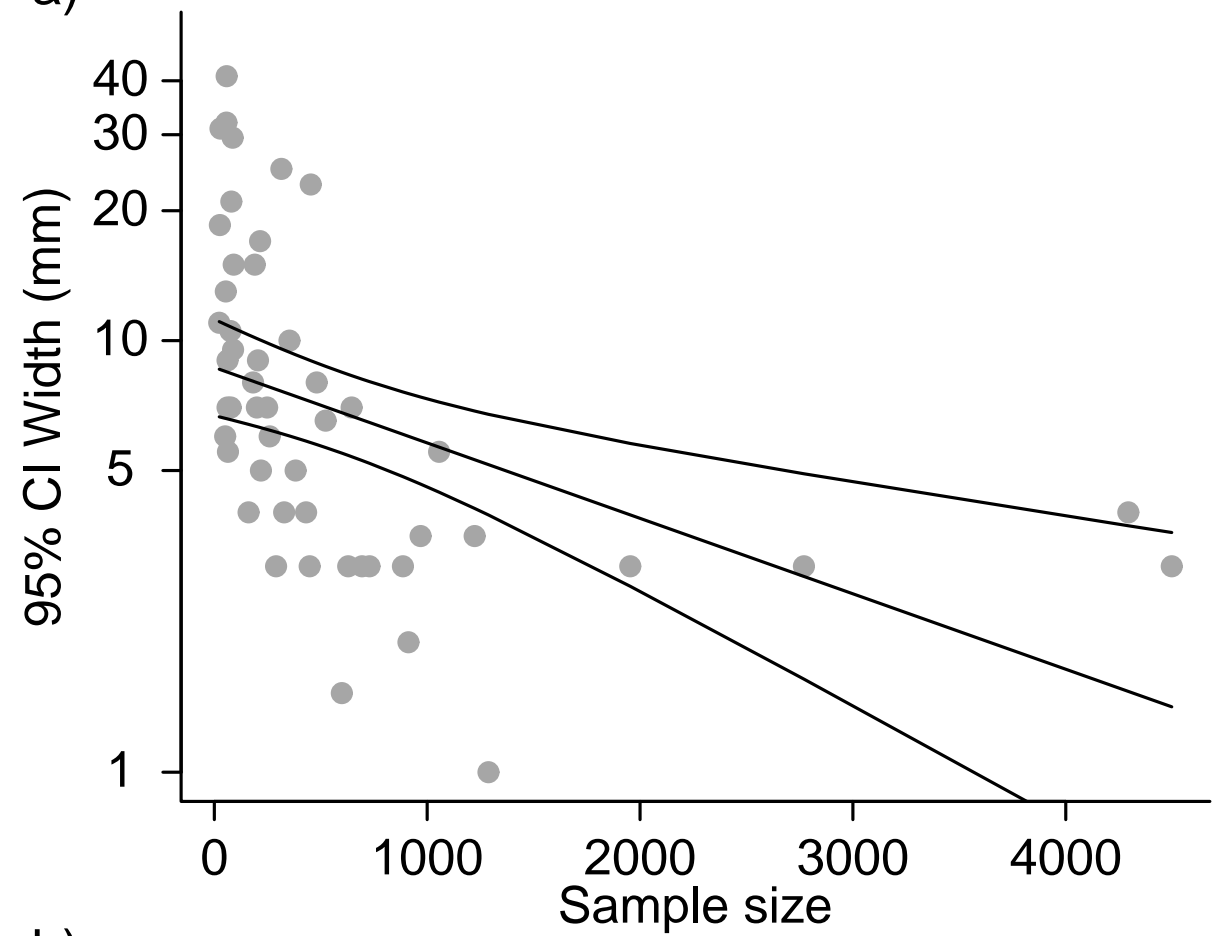

b)

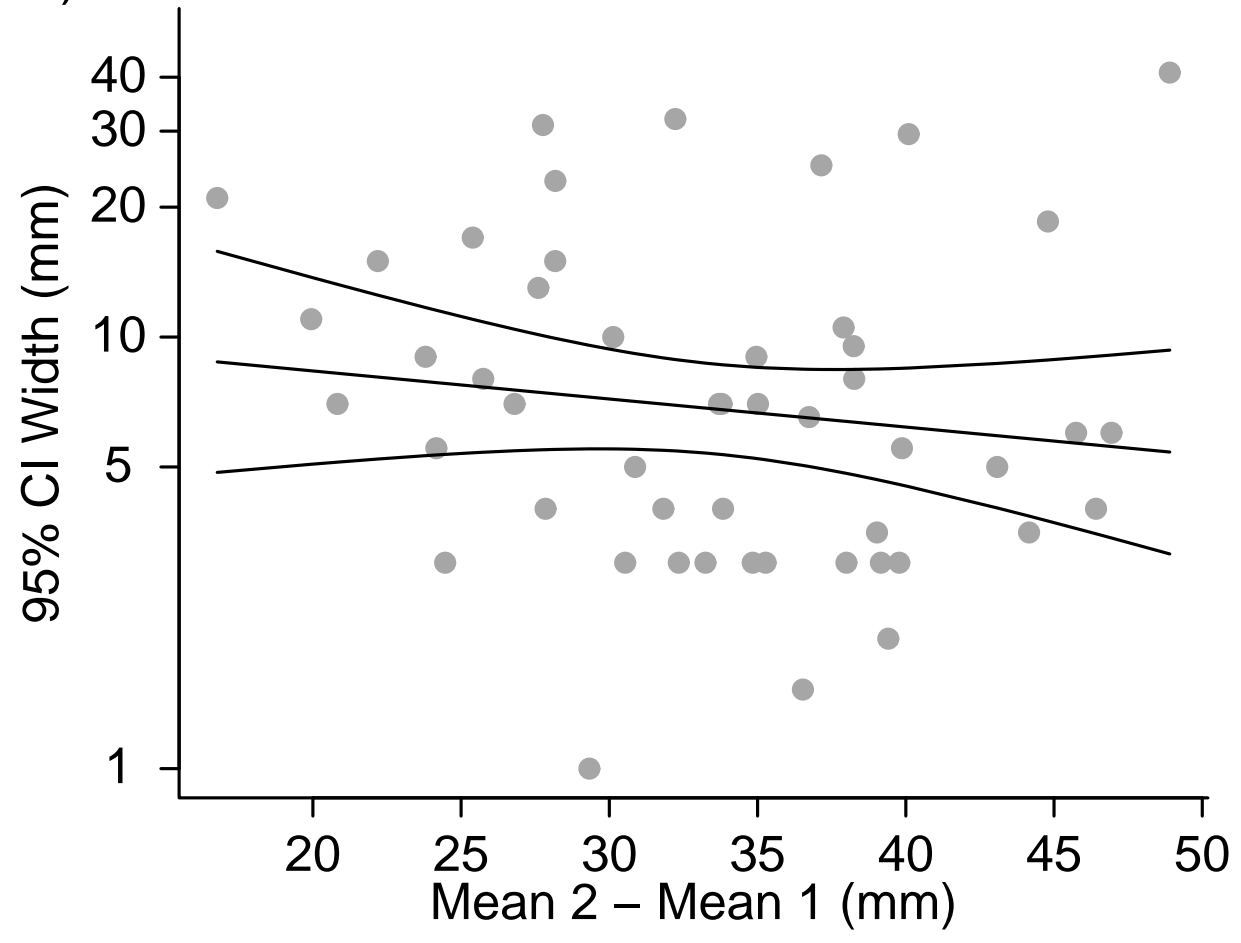



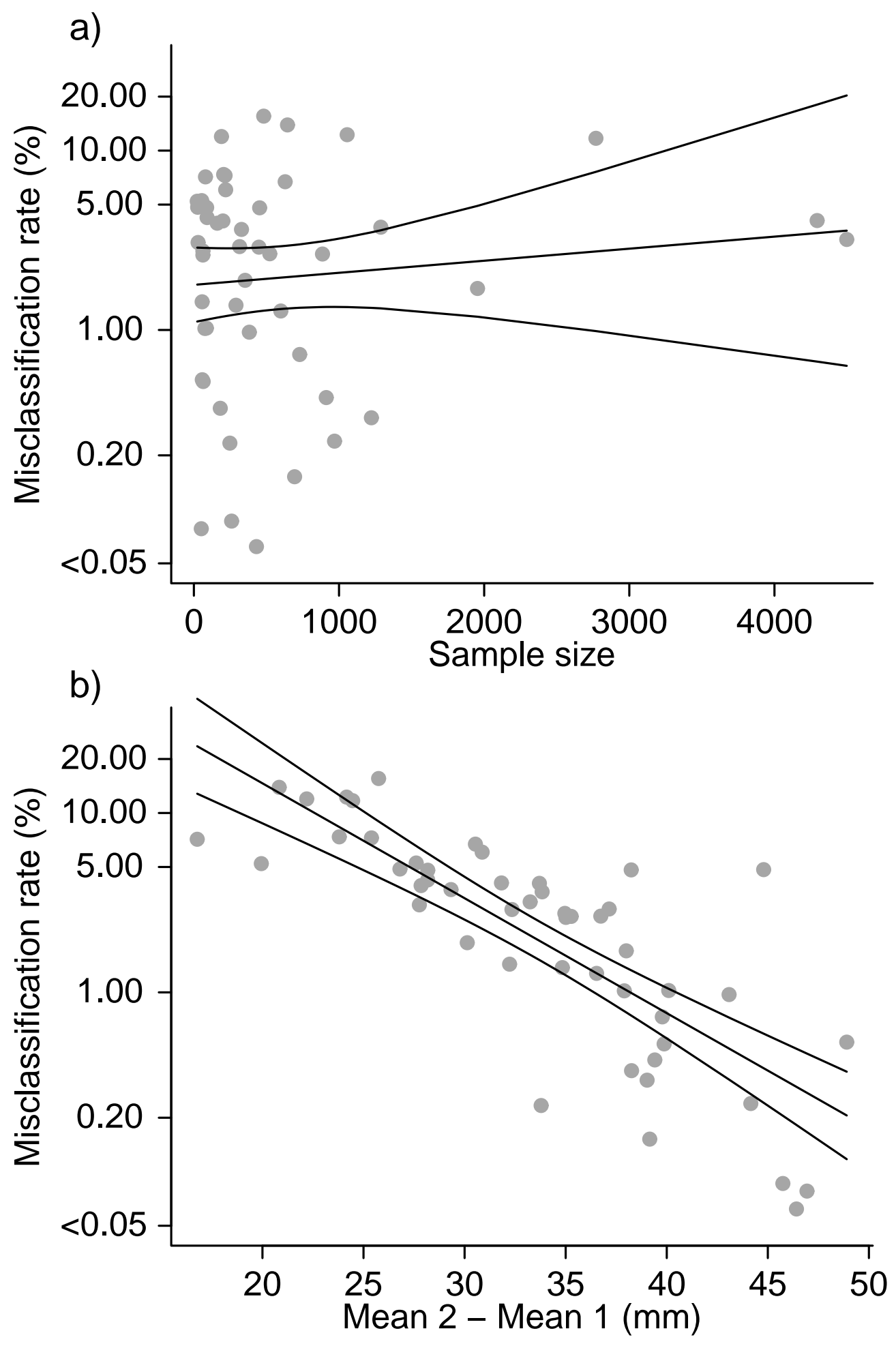